\title{
Living with painful diabetic neuropathy
}

Citation for published version (APA):

Kanera, I. M., van Laake-Geelen, C. C. M., Ruijgrok, J. M., Goossens, M. E. J. B., de Jong, J. R., Verbunt, J. A., Geerts, M., Smeets, R. J. E. M., \& Kindermans, H. P. J. (2019). Living with painful diabetic neuropathy: insights from focus groups into fears and coping strategies. Psychology \& Health, 34(1), 84105. https://doi.org/10.1080/08870446.2018.1518526

Document status and date:

Published: 01/01/2019

DOI:

10.1080/08870446.2018.1518526

Document Version:

Publisher's PDF, also known as Version of record

Document license:

Taverne

Please check the document version of this publication:

- A submitted manuscript is the version of the article upon submission and before peer-review. There can be important differences between the submitted version and the official published version of record.

People interested in the research are advised to contact the author for the final version of the publication, or visit the DOI to the publisher's website.

- The final author version and the galley proof are versions of the publication after peer review.

- The final published version features the final layout of the paper including the volume, issue and page numbers.

Link to publication

\footnotetext{
General rights rights.

- You may freely distribute the URL identifying the publication in the public portal. please follow below link for the End User Agreement:

www.umlib.nl/taverne-license

Take down policy

If you believe that this document breaches copyright please contact us at:

repository@maastrichtuniversity.nl

providing details and we will investigate your claim.
}

Copyright and moral rights for the publications made accessible in the public portal are retained by the authors and/or other copyright owners and it is a condition of accessing publications that users recognise and abide by the legal requirements associated with these

- Users may download and print one copy of any publication from the public portal for the purpose of private study or research.

- You may not further distribute the material or use it for any profit-making activity or commercial gain

If the publication is distributed under the terms of Article $25 \mathrm{fa}$ of the Dutch Copyright Act, indicated by the "Taverne" license above, 


\title{
Living with painful diabetic neuropathy: insights from focus groups into fears and coping strategies
}

\author{
Iris M. Kanera, ${ }^{a, b}$ (D) Charlotte C. M. van Laake-Geelen ${ }^{b, c, d}$, Joop M. Ruijgrok ${ }^{b, e}$,
} Marielle E. J. B. Goossens ${ }^{b}$, Jeroen R. de Jong ${ }^{b, c}$, Jeanine A. Verbunt ${ }^{b, c, d}$ (iD, Margot Geerts ${ }^{f}$, Rob J. E. M. Smeets ${ }^{b, g}$ and Hanne P. J. Kindermans ${ }^{b, h}$

\begin{abstract}
${ }^{a}$ Research Centre for Nutrition, Lifestyle, and Exercise, Faculty of Health, Zuyd University of Applied Sciences, Heerlen, The Netherlands; ${ }^{b}$ Department of Rehabilitation Medicine, Maastricht University,

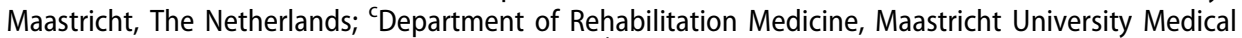
Centre (MUMC+), Maastricht, The Netherlands; ${ }^{\mathrm{d}}$ Adelante Centre of Expertise in Rehabilitation and

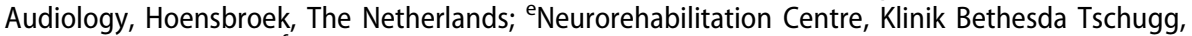
Tschugg, Switzerland; 'Department of Neurology, Maastricht University Medical Centre (MUMC+), Maastricht, The Netherlands; 'Libra Rehabilitation and Audiology, Eindhoven, The Netherlands; ${ }^{h}$ Department of Clinical Psychological Science, Maastricht University, Maastricht, The Netherlands
\end{abstract}

\begin{abstract}
Objective: Painful diabetic neuropathy (PDN) is known to negatively affect quality of life. Being physically active is a crucial part of successful diabetes self-management, but regimen adherence is often low. Coping strategies and fears have shown to be related to less physical activity (PA). The aim of the present study was to obtain more in-depth information on psychological risk factors leading to less PA in persons with PDN.

Design: Three semi-structured focus group interviews were conducted with a representative sample of persons with PDN $(N=12)$. Data were transcribed verbatim and analysed using a hybrid method of thematic analyses and a grounded theory approach.

Main Outcome Measures: Fears and coping strategies related to PA in persons with PDN.

Results: Several specific fears were identified; fear of hypoglycaemia, fear of pain increase, fear of total exhaustion, fear of physical injury, fear of falling, fear of loss of identity, and fear of negative evaluation by others. To cope with these fears, avoidance, remaining active, cognitive distraction, and acceptance strategies were described.

Conclusion: In persons with PDN, diabetes-related fears and pain-related fears play a role in less engagement in PA, indicating the need for new methods for improving self-management in persons with PDN.
\end{abstract}

\section{ARTICLE HISTORY}

Received 24 August 2017 Accepted 5 July 2018

\section{KEYWORDS}

Diabetes; neuropathic pain; fear; coping; self-management; diabetes self-care

CONTACT C. C. M. van Laake-Geelen, MD c.laake@adelante-zorggroep.nl $\supseteq$ Adelante Centre of Expertise in Rehabilitation and Audiology, P.O. Box 886430 AB, E Hoensbroek, The Netherlands

4 Supplemental data for this article can be accessed here 


\section{Introduction}

Painful Diabetic Neuropathy (PDN) affects at least $25 \%$ of all persons with diabetes (Abbott, Malik, van Ross, Kulkarni, \& Boulton, 2011; Van Acker et al., 2009). Unfortunately, current pharmacological treatment does not provide sufficient pain relief and can have side effects in many persons with PDN (Brix Finnerup, Hein Sindrup, \& Staehelin Jensen, 2013; Gilron, Baron, \& Jensen, 2015). In conjunction with diabetes, neuropathic pain (NP) can lead to a myriad of symptoms such as insomnia, high levels of anxiety, depression, and social and physical limitations, which have a considerable impact on quality of life (QoL) (Green, Feher, \& Catalan, 2000; Jain, Jain, Raison, \& Maletic, 2011; Sadosky et al., 2013). Insights into the complexity of living with these problems and personalised treatment seem to be needed to support persons with PDN in improving their daily life functioning.

An important part of diabetes self-management is engaging in physical activity (PA). Being physically active can reduce the prevalence and severity of complications, while sedentary behaviour can lead to a higher risk of negative health outcomes such as vascular and neurological complications (Heinrich, Schaper, \& de Vries, 2010; Kluding et al., 2012). Despite the beneficial effects of PA, persons with type 2 diabetes mellitus (DMII) are less engaged in moderate or vigorous PA compared to individuals without DMII (Morrato, Hill, Wyatt, Ghushchyan, \& Sullivan, 2007; van Sloten et al., 2011). Also, PA interventions show inconsistent effects on increasing and maintaining PA in persons with DMII, which might be due to the complexity of the diabetic problems, NP, and/or fears (Geelen et al., 2016; Geelen, Smeets, et al., 2017; Heinrich et al., 2010).

It has been suggested that persons with PDN could perceive fears such as agoraphobia, fear of complications, self-management in public, and anxiety after diabetes diagnosis; all of which may affect PA (Balhara \& Sagar, 2011; Geelen, Smeets, et al., 2017; Petrak, 2007). For example, fear of hypoglycaemia might lead to dysfunctional self-management behaviour such as avoiding PA and overeating in certain subgroups (Ahola \& Groop, 2013; McCoy et al., 2013). Next to these possible diabetes-related fears, fears specifically related to the NP may also contribute to heightened anxiety levels and that may lead to additional behavioural consequences in persons with PDN (Geelen, Smeets, et al., 2017). It is known from studies in persons with PDN and other chronic pain conditions that catastrophic thinking about pain could be an important determinant of disability and diminished QoL (de Jong, Vlaeyen, de Gelder, \& Patijn, 2011; Geelen, Kindermans, van den Bergh, \& Verbunt, 2017; Gheldof et al., 2010; Sullivan, Lynch, \& Clark, 2005). Therefore, it is plausible that persons who feel anxious about their NP and its consequences may also tend to avoid PA because of these fears.

The aim of the present study was to gain more in-depth information on the personal experiences of potential fears and PDN-related coping strategies, in order to obtain a better understanding of the complexity of PDN. The findings of this study could enable us to design a personalised treatment strategy that aims to improve physical and psychological wellbeing in persons with PDN. 


\section{Methods}

\section{Participants}

Potential participants were selected by a specialised outpatient clinic for persons with PDN in the Netherlands (Maastricht University Medical Centre). Medical staff assessed eligibility (diabetes type 2, peripheral neuropathy, NP) during medical consultations, or by reviewing patient files. Participants were included if they were over 18 years of age, Dutch-speaking, diagnosed with type 2 diabetes and peripheral neuropathy (physical examination and by neurophysiological testing such as electromyography), with moderate to severe NP, and who were moderately to severely disabled due to pain. Furthermore, participants were selected by purposeful sampling, based on stringent criteria to reflect the appropriate population as closely as possible. Homogeneity was required since the research topics (pain, fears) might be only relevant to certain segments of the PDN-population. We intentionally chose to select this specific population with severe complaints, in order to be able to obtain sufficient in-depth information about psychosocial factors that may play a role in PDN related pain and fears. Final inclusion of participants was performed according to a predefined set of assessment instruments, all definitions and cut-off values are described further on (Eligibility assessment). Participants with severe psychiatric problems and chronic pain syndromes due to other causes were excluded.

Eligible persons with PDN were asked whether they were interested in more information. Those who were interested were sent a hardcopy information package by mail that included a detailed study description, along with an informed consent form. Persons with PDN who were willing to participate were asked to send the signed informed consent form to the researchers in an enclosed, pre-paid envelope and for non-respondents one follow-up phone call was done two weeks later. Self-report questionnaires were sent to the consenting participants to collect baseline data and assess eligibility criteria such as level of disability, NP, and psychiatric problems. Participants were asked to return completed questionnaires in an enclosed, pre-paid envelope. When eligible, the respondents were invited to participate in a focus group interview (FG). The present study was approved by the Medical Research Ethics Committee University Hospital Maastricht, Maastricht University (METC 11-4-045). Informed consent was obtained from all individual participants included in the study.

\section{Measures}

\section{Eligibility assessment}

To measure pain intensity the Numeric Rating Scale (NRS) (Jensen, Karoly, \& Braver, 1986), ranging from 0 (no pain) to 10 (maximum pain) was verbally applied, and a score $\geq 5$ was used as selection criterion for participation.

Furthermore, the subscale Pain Severity Index (PSI) of the self-report modified Brief Pain Inventory for diabetic peripheral neuropathy (BPI-DPN) was utilised (Zelman, Dukes, Brandenburg, Bostrom, \& Gore, 2005; Zelman, Gore, Dukes, Tai, \& Brandenburg, 2005), which included four items (worst pain, least pain, average pain, and pain now) using 0 (no pain) to 10 (maximum pain) numeric rating scales. In previous studies, the 
Cronbach's alpha has shown to be high (0.94) for this scale (Zelman, Gore, et al., 2005). In our study with a small sample size, Cronbach's alpha over the 4 items was 0.75. The mean of all scores was expressed as a PSI and classified into mild (0-3), moderate (4-6), and severe (7-10), and a score of $\geq 5$ was used as an additional inclusion criterion.

To confirm PDN, the validated Diabetic Neuropathy Symptom Score (DNS) (Meijer et al., 2002) was used, comprising four-items (unsteadiness, NP, paraesthesia, numbness), ranging from 0 to 4 with a score of $\geq 1$ indicating the presence of PDN. Correlations between the DNS and Neuropathy Symptom Score has shown to be high (Spearman $r=0.88$ ) (Meijer et al., 2002).

The degree of NP was assessed using seven self-report questions of the Douleur Neuropathique 4 questionnaire (DN4) (Bouhassira et al., 2005; van Seventer et al., 2013), measuring symptoms such as pain characteristics and abnormal sensations (tingling, pins and needles, numbness, itching). The total score range was $0-7$ with a diagnostic cut-off score of $\geq 3$. The DN4 has shown to be significantly related to neurological and electrophysiological measurements and to the Short-Form McGill Pain Questionnaire in persons with PDN. Furthermore, the DN4 and DN4-interview scores showed a high diagnostic accuracy for PDN with areas under the receiver operating characteristic curve of 0.94 and 0.93, respectively (Spallone et al., 2012).

Pain disability was measured using the validated Pain Disability Index - Dutch Version (PDI-Dutch) (Soer et al., 2013; Tait, Chibnall, \& Krause, 1990), comprising seven items that asses the degree of pain interference during daily living activities, work, leisure time, and sports. Items were scored on a NRS from 0 (no disability) to 10 (maximum disability) with a total score range of $0-70$, and a score $\geq 29$ used as inclusion criterion. The internal consistency of the PDI-Dutch has shown to be good in persons with back pain (Cronbach's $\alpha$ 0.83-0.86) (Soer et al., 2013). In our population, the Cronbach's $\alpha$ was 0.75 .

\section{Demographic and psychological characteristics}

Baseline information was collected using standard questions on age (years), gender (male/female), marital status (with partner yes/no), education level (low/medium/high), employment status (retired/sick leave/voluntary work/no employment/self-employed), medication use, and comorbidities.

Anxiety and depression were assessed using the Hospital Anxiety and Depression Scale (HADS) (Zigmond \& Snaith, 1983). The questionnaire consists of 14 items, 7 evaluating cognitive and emotional aspects of anxiety (HADS-A) and 7 representing the cognitive and emotional aspects of depression (HADS-D). Each question is scored on a 4-point Likert scale, ranging from 0 to 3, where a higher score represents more severe depression or anxiety. In a group of persons with chronic pain (fibromyalgia), the Cronbach's $\alpha$ of HADS-D and HADS-A were 0.82 and 0.81 , respectively (Nam, Tin, Bain, Thorne, \& Ginsburg, 2014). In our population, the Cronbach's $\alpha$ of HADS-D and HADS-A were 0.84 and 0.79 , respectively.

Fear avoidance beliefs were measured using the Dutch version of the Tampa Scale for Kinesiophobia (TSK-DV) (Vlaeyen, Kole-Snijders, Boeren, \& van Eek, 1995; Vlaeyen, Kole-Snijders, Rotteveel, Ruesink, \& Heuts, 1995). Test-retest reliability has shown to 
range from $r=0.64-0.80$ (Swinkels-Meewisse, Swinkels, Verbeek, Vlaeyen, \& Oostendorp, 2003). The internal consistency of the TSK has shown to be good (Cronbach's $\alpha=0.81$ ) (Roelofs, Goubert, Peters, Vlaeyen, \& Crombez, 2004). In this study, the Cronbach's $\alpha$ was 0.71 .

Pain catastrophizing was assessed using the Pain Catastrophizing Scale (PCS) Dutch Version by Crombez and Vlaeyen (The PCS, Unpublished authorised translation, 1996). Van Damme, Crombez, Bijttebier, Goubert, and Van Houdenhove (2002) have shown the Dutch PCS demonstrated good reliability and validity. In our sample, the Cronbach's $\alpha$ was 0.88 . This questionnaire measures negative thoughts and beliefs during actual or anticipated painful experiences. The items are scored on a five-point Likert scale with scoring possibilities ranging from 'not at all' (score $=0$ ) to 'always' (score $=4$ ). The PCS scores can range from 0 to 52 . High scores indicate that more catastrophic thoughts or feelings are experienced. The PCS has shown to have adequate to excellent internal consistency (Sullivan, Bishop, \& Pivik, 1995).

The Short Form Health Survey (SF-36) was used to measure QoL (Aaronson et al., 1998; Ware \& Sherbourne, 1992). The SF-36 is a 36-item health survey comprised of eight subscales measuring functional health and well-being (Ware, Kosinski, Dewey, \& Gandek, 2000). The psychometric properties have been evaluated across populations with various conditions. Previous studies in chronic pain patients have shown a Cronbach's $\alpha$ ranging from 0.79 to 0.91 (Wittink, Turk, Carr, Sukiennik, \& Rogers, 2004). In our sample, the Cronbach $\alpha$ for the total score was 0.71 . Cronbach $\alpha$ 's for the subscales were: physical functioning $\alpha=0.78$; role limitation due to physical health $\alpha=0.78$; role limitations due to emotional problems $\alpha=0.87$; energy/fatigue $\alpha=0.67$; emotional well-being $\alpha=0.77$; social functioning $\alpha=0.65$; pain $\alpha=0.96$ and general health $\alpha=0.84$, respectively.

\section{Design}

In the present study, semi-structured FG interviews were conducted to explore in-depth information about potential fears and cognitions, in order to understand and interpret behaviours and the underlying motives within the situational context of persons with PDN. The consolidated criteria for reporting qualitative research (COREQ) were used to aggregate and report information on data collection and analysis (Tong, Sainsbury, \& Craig, 2007).

The interviews were guided by two researchers and lasted 120 minutes each and were moderated by one of the authors (IK) and facilitated by a research assistant (medical student). The interviewer was an experienced physiotherapist in the field of pain-/fear rehabilitation experienced and trained in conducting FG interviews, which was beneficial to ask specific questions to obtain in-depth information. The participants did not know the interviewer and facilitator in advance. The FG's were conducted in a recording studio, videotaped, and field notes were taken. In addition, participants were encouraged to answer moderators' questions, and to talk and interact with each other. Probe questions, such as 'Would you explain further?' were asked to elicit additional information. Interview questions are provided in Table 1. These 
Table 1. Examples of the questions used in the focus groups.

- Would you please describe how you occupy yourself every day?

- Tell me about your experience about how to live with pain?

- What is changed in your life through the pain?

- Due to which complaints do you feel restricted?

- Are you more cautious than other fellow diabetes patients who do not have pain?

- In what situations do you feel uncertain?

- What makes you cautious?

- When you think about the future with diabetes, is there anything where you are worried about?

- Do these thoughts or feelings affect your daily activities?

- Is there anything else I have forgotten to ask you about the impact of the pain on your daily life?

questions were discussed and adapted by a rehabilitation physician, a physician of internal medicine, and a psychologist. Three interviews were performed.

In line with the grounded theory approach, prior clinical knowledge on possible problem areas of persons with PDN were used as a starting point for topics and probes in the preliminary discussion guide (Brod, Tesler, \& Christensen, 2009; Cutcliffe, 2005; Smith, 2015). Also, in accordance with the grounded theory approach, the research process was not pre-determined, but evolved by a process of systematic data analysis (Morgan \& Krueger, 1998; Mortelmans, 2011). The moderator led the discussion based on a semi-structured interview guide. The FG questions were categorised into different types (opening, introductory, transition, key, ending) on the basis of Krueger's method (Morgan \& Krueger, 1998). Initially, unbiased open questions were asked, such as 'Tell me about your experience about how to live with pain', and probes were changed based on respondents' statements for further clarification (Table 1) (Brod et al., 2009). The participants were encouraged to share and compare their experiences and emotions, and to comment on each other (Morgan \& Krueger, 1998). Experiences and thoughts were prompted by comments of other group members and certain ideas were accepted or rejected by individuals. This interaction between the participants provided insights and in-depth understanding. Theoretical understanding was developed as the data were gathered and analysed and the research process stopped when no new understanding emerged (Dew, 2007). The point at which theoretical saturation was achieved was the indicator of sample size as well as the required number of FG in qualitative research (Cutcliffe, 2005). Typically, one FG is composed of less than ten participants who share a common experience (Smith, 2015).

\section{Data collection and analysis}

Data collection and analysis were interrelated and started when the first data were collected (Cutcliffe, 2005). The FG's were video-recorded and the conversations were fully transcribed in NVivo 8 directly after FG completion ('NVivo qualitative data analysis Software Version $8^{\prime}$, 2008). According to the grounded theory approach, open codes were assigned to all relevant phenomena through line-byline coding by two researchers who worked independently (IK; physiotherapist/ health scientist and NS; medical and psychology student). The derived codes of the two researchers were compared and discussed and merged into one codebook. All potentially relevant issues were incorporated into the next interview guide. After 
completing the subsequent FG, relevant phenomena from the corresponding FG were coded either by using existing matching codes from the previous interview, or by creating new codes. Accordingly, two researchers coded each interview independently. Prior to the study, we defined that when the codes differed, they were to be discussed by the two researchers until agreement was reached on the new codebook. In practice, this situation occurred rarely. This process was conducted systematically, until no new topics appeared and theoretical saturation was reached. The created codes of the final code book after completion of all interviews were categorised into higher order themes. In this process of categorisation, a group of clinical experts consisting of three experts in the field of health psychology and three experts in rehabilitation medicine were involved by discussing and consenting on the higher order themes.

\section{Results}

\section{Participant characteristics}

In total, three FG took place until theoretical saturation was achieved. Of the 13 invited participants with PDN, 12 attended one of the three FG with four participants each. The reason for one dropout was admission to a hospital. Table 2 shows the baseline characteristics of all participants.

\section{Data coding}

During data analysis, 68 codes were discovered during the first interview. According to the grounded theory approach, the emerged codes were wide ranging and included topics such as pain and physical complaints (e.g. hypoglycaemia, sores, insomnia, and fatigue), limitations concerning walking, unsteadiness, standing still, and walking stairs, falling, cycling, and commuting. Furthermore, risks with regard to excessive physical exertion in different situations and the expected negative consequences (e.g. pain, complete exhaustion, dependency on others) were mentioned, and the way of dealing with physical demands and social situations (e.g. avoidance, using aids). Moreover, topics concerning emotional problems emerged (e.g. pain, depressive symptoms, end-of-life topics). In the second FG, most of these topics were confirmed and further elaborated upon. In addition, 12 new codes were added to the codebook (e.g. embarrassment, distraction, (non-) acceptance, physical training, not been taken seriously, employment issues, relational problems, travelling, custom-made shoes, further physically decline, frustrations). During the third interview, again, most of the topics were in line with the topics from the two prior FG; however, no new themes emerged. All relevant phenomena from data of the third interview could be categorised into the 80 existing codes, which indicated that the point of theoretical saturation was achieved and no further FG were necessary. Subsequently, the 80 codes were categorised into higher order themes. The higher order themes were seven types of fears and four types of coping strategies. The final code book is provided as supplemental data. 
Table 2. Demographic, medical, and psychological characteristics of the participants $(N=12)$.

\begin{tabular}{|c|c|}
\hline & $N(\%) /$ Mean $\pm \mathrm{SD}$ \\
\hline Male gender & $8(66.7)$ \\
\hline Age, mean (SD) & $65.3 \pm 10.26$ \\
\hline \multicolumn{2}{|l|}{ Marital status } \\
\hline With partner & $11(91.7)$ \\
\hline \multicolumn{2}{|l|}{ Education $^{\mathrm{a}}$} \\
\hline Low & $7(58.3)$ \\
\hline Medium & $3(25)$ \\
\hline High & $2(16.7)$ \\
\hline \multicolumn{2}{|l|}{ Employment status } \\
\hline Retired & $4(33.3)$ \\
\hline Sick leave & $3(25)$ \\
\hline Voluntary work & $1(8.3)$ \\
\hline No employment & $2(16.7)$ \\
\hline Self-employed & $2(16.7)$ \\
\hline Number of years DMII & $17.9 \pm 9.1$ \\
\hline Number of years PDN & $11.3 \pm 6.5$ \\
\hline Depending on electric wheelchair & $5(41.7)$ \\
\hline \multicolumn{2}{|l|}{ Administering of insulin } \\
\hline Oral & $3(25)$ \\
\hline Injection & $8(66.7)$ \\
\hline Pump & $1(8.3)$ \\
\hline Pain Severity Index $(0-10)^{b}$ & $6.5 \pm 1.2$ \\
\hline Douleur Neuropathique 4 questionnaire (DN4) (0-4) & $3.6 \pm 0.6$ \\
\hline Pain Disability Index $(0-70)^{\mathrm{b}}$ & $45.3 \pm 8.7$ \\
\hline Fear avoidance (TSK-DV) $(17-68)^{\mathrm{b}}$ & $40.6 \pm 8.0$ \\
\hline Pain Catastrophizing Scale, $(0-52)^{b}$ & $23.3 \pm 9.7$ \\
\hline \multicolumn{2}{|l|}{ HADS } \\
\hline Anxiety $(0-21)^{\mathrm{b}}$ & $7.8 \pm 3.4$ \\
\hline Depression $(0-21)^{\mathrm{b}}$ & $9.4 \pm 4.3$ \\
\hline \multicolumn{2}{|l|}{ Quality of Life (SF-36), $(0-100)^{c}$} \\
\hline Physical functioning & $23.3 \pm 15.1$ \\
\hline Role functioning physical & $6.3 \pm 15.5$ \\
\hline Role functioning emotional & $50 \pm 46.1$ \\
\hline Social functioning & $58.3 \pm 20.9$ \\
\hline Bodily pain & $51 \pm 8.9$ \\
\hline Mental health & $27.1 \pm 16.7$ \\
\hline Vitality & $41.7 \pm 16.4$ \\
\hline General health & $31.3 \pm 19.6$ \\
\hline
\end{tabular}

Notes: PDN, painful diabetic neuropathy; DM, diabetes mellitus type 2; TSK_DV, Tampa Scale for Kinesiophobia, Dutch Version (higher scores predict higher disability); HADS, Hospital Anxiety and Depression Scale; SF-36, Short Form Health Survey.

'Low education': lower vocational education; 'medium education': medium general secondary education; 'high education': higher vocational education.

${ }^{\mathrm{b}}$ Total score range (higher scores indicate more problems).

${ }^{\mathrm{C}}$ Total score range of all subscales (higher scores indicate better health).

\section{Fears}

\section{Fear of hypoglycaemia}

The majority of insulin-dependent participants were afraid to (re-)experience hypoglycaemia, and therefore inject insulin, stick to their diet, and perform PA very carefully. Notably, some participants mentioned that they maintained a slightly higher blood glucose level than recommended, in order to prevent hypoglycaemia.

Quote (male, 56 years, insulin treatment, 22 years of PDN, living together, sick leave, no walking aid): I had a period of hypoglycaemia when I was driving and I caused an accident. I never dare to step into the car again. 


\section{Fear of an increase in pain}

After many years suffering from DMII, most of the respondents were used to diabetesrelated complaints and could cope with it. However, the additional occurrence and presence of pain such as NP had a substantial debilitating effect on their functioning in daily life. In certain situations, the level of pain increased, which was described as a horrible experience. From respondents' perspective, the increase in pain was probably caused by performing PA that was too exhausting. When perceived severe pain, some of the participants were not able to cope with this high level of pain and experienced feelings of helplessness and loss of control. Consequently, the most fearful persons with PDN avoided as much as possible physical activities and preferred to stay at home. One participant even prefers to stay in bed as much as possible.

Quote I (female, 76 years, oral medication, married, 2 years of PDN, housewife, mobile scooter): I avoid going too far, because then I cannot cope anymore.

Quote II (male, 57 years, oral medication, married, 12 years of PDN, part-time sick leave, wheelchair): I know exactly when the pain attack will come. I start sweating and then it happens. It feels like getting crushed by hydraulic scissors, getting tighter and tighter (...).

\section{Fear of total exhaustion}

A substantial majority of participants experienced one or more situations of complete exhaustion. Usually, this feeling of total exhaustions occurred unexpected and suddenly during daily activities. In these situations, persons with PDN felt powerless, helpless and embarrassed. Additionally, they were not able to continue their activities and were in need for help from others. Therefore, fearful participants mentioned that they avoided exhausting themselves. For example, when walking outside, respondents remain deliberately close to a possibility to sit down.

Quote (male, 57 years, oral medication, married, 12 years of PDN, part-time sick leave, wheelchair): I am not going to exhaust my body. When I move, I am in a lot of pain afterwards. I have to avoid it in any case.

\section{Fear of physical injury}

Due to the numbness and/or painful skin sensitivity of the feet, a number of persons with PDN were afraid of developing sores on their feet and lower legs. In the past, they experienced that those sores in most instances hardly healed. All participants avoided walking long distances, despite wearing custom-made orthopaedic shoes. To prevent physical injury, such as sores or severe complaints (e.g. heart conditions), persons with PDN reported to avoid going on excursions or vacation. Furthermore, they did not trust other unknown or foreign health care systems in case medical care would be required.

Quote (male, 56 years, insulin treatment, divorced, 13 years of PDN, incapacity for work, mobile scooter): Actually, I am careful with everything and do not go on holiday to foreign destinations. If something would happen to me, they may not be able to help me. 


\section{Fear of falling}

All participants acknowledged being afraid of falling when walking on cobblestones, stairs, uneven or slippery surfaces, walking through busy streets, and when using public transportation. They reported that the numbness, pain, and unsteadiness of their legs and feet causes a feeling of instability with makes them cautious and hypervigilant. Therefore, persons with PDN reported to be very hesitant to walk, especially in a crowded environment. Additionally, several participants needed support from their partners, or used walking aids such as a walking stick, walker, or wheelchair.

Quote I (female, 65 years, insulin treatment, married, 8 years of PDN, charity work, no walking aid): I am afraid of falling in the middle of the city centre, all people watching me.

Quote II (male, 51 years, oral medication, married, 7 years of PDN, working in own business, no walking aid): I have to climb over the edge of my bath. This results in lifethreatening situations.

\section{Fear of loss of identity}

The participants reported to be considerably restricted in daily life activities, housekeeping, work, hobbies, sports, social activities, and traveling. They had become more and more physically limited and increasingly dependent on others. As a result, they said to have lost meaningful tasks and responsibilities, which caused feelings of loss of purpose in life and loss of their identity. In some cases, these thoughts led to anger and unwillingness to accept the situation and further deterioration, which resulted in performing dangerous activities to prove themselves.

Quote I and II (male, 56 years, insulin treatment, living together, 22 years of PDN, sick leave, no walking aid): I am afraid not to be able to stand long enough to finish a conversation. (...) I am afraid of not being able to drive my car to get to work/hobby's/ social activities.

\section{Fear of negative evaluation}

More than half of the participants expressed the fear of being negatively judged by others. This was illustrated by situations in which they felt vulnerable in the presence of others, with a consequence of perceived negative attention and negative judgements. Walking unsteadily, walking with a walking aid, being exhausted, falling, having a hypoglycaemia, and injecting insulin in public were reported as very embarrassing situations. In these situations, other people could make them feel 'ill and pathetic', and they did not feel taken seriously. For this reason, activities such as going for a walk and going shopping in public were usually avoided by respondents.

Quote I and II (male, 56 years, insulin treatment, living together, 22 years of PDN, sick leave, no walking aid): I do not want to look and feel like an old man (...) I feel less attractive when I have to walk with a walking aid.

\section{Coping with PDN}

Alongside the aforementioned fears, a number of coping strategies were identified, which will be further elaborated in the following paragraphs. 


\section{Being active despite PDN}

The majority of participants emphasised that remaining physically and socially active despite pain and limitations is of great value. However, most participants preferred not to exercise too often. Examples of activities were engagement in longstanding habits (e.g. daily visit of family), social engagements (e.g. work, voluntary work, care for grandchildren), and participating in public celebrations, such as carnival. Their rationale to stay active was to fulfil social roles to which they felt obliged, receiving appreciation, and having a purpose in life. The majority of participants emphasised that physical efforts must be adapted to personal capabilities. The majority of respondents agreed that remaining physically active helped in preventing further deterioration and becoming overly dependent upon others. Valuable strategies in helping to stay active were a regular daily schedule (e.g. walking the dog at fixed times), and appointments with others. The participants emphasised that a certain internal motivation in combination with external support is required to remain active. Finally, exercise support by health professionals was perceived beneficial when carefully tailored to the participants' individual needs.

Quote I (male, 51 years, oral medication, married, 7 years of PDN, working in own business, no walking aid): I do not let the pain ruin my life. I just do what I think I have to, and often, I go too far. It destroys me, but I benefit from it. I get a feeling of satisfaction. Yes, I still can do this!

Quote II (female, 65 years, insulin treatment, married, 8 years of PDN, charity work, no walking aid): Every day I walk 30 minutes together with my husband. I slowly built this up. Afterwards I feel a lot of pain, but if I would stop doing that, I could walk no longer, soon.

Quote III (female, 61 years, insulin treatment, married, 4 years of PDN, housewife, wheelchair): A little bit of housekeeping, preparing a meal, yes, it costs a lot of effort and pain. But, I want to do that. That is the only purpose I have in my life: caring for my husband and daughter as good as I can.

\section{Distraction and attention}

Importantly, distraction from pain by focusing on a specific activity, hobby, or task was reported to provide pain relief. Some examples of mentioned activities were knitting garments, being involved in interesting tasks and conversations, and participating in aqua jogging lessons. An important characteristic of distraction was that the individuals' attention was focused entirely on the activity, which caused distraction from pain and even pain relief. However, directing attention towards the pain and other complaints led to an increase in pain and other sensations. This phenomenon was reported to often occur during moments of resting.

Quote I (male, 70 years, insulin treatment, married, 13 years of PDN, charity work, no walking aid): If you are busy with something you enjoy, it gives you a mental distraction. When I'm working with wood, I feel no pain.

\section{Avoidance}

Avoidance was the most frequently stated strategy to cope with PDN. Activities declined gradually over time by steady reductions in the frequency and intensity (e.g. 
decrease in walking bouts, distance, and speed). Importantly, participants described fears as the primary reasons for avoidance. In particular, participants avoided those activities, which they were not used to do and which were perceived to be too effortful. Furthermore, a number of participants stated that the use of external aid and aids made them lazy (e.g. wheelchair, walker, stair elevator). These statements exemplify that environmental factors, such as social support, housing conditions, adaptations in homes, and the availability of aids might also be related to avoidance behaviour and a decrease in PA.

Quote I and II (male, 57 years, oral medication, married, 12 years of PDN, part-time sick leave, wheelchair): Diabetes and walking, yes okay, but, I can tell you, it is absolutely not possible to walk with neuropathic pain. That does not work. When you have to walk with neuropathic pain, then you have a bad time. (...) I do not go on a home trainer, cycling uphill, afterwards suffocating in pain, because the therapist wants me to do that. No, I am sorry, that makes no sense to me.

Quote III (male, 56 years, insulin treatment, 22 years of PDN, living together, sick leave, no walking aid): There is much bullying at my work. If I would use a walker, I would be an idiot. I am on sick leave now.

\section{Acceptance and resignation}

Acceptance or resignation of complaints was often referred to as an important coping strategy. All participants reported that it was difficult to accept that the pain and restrictions were permanent. They explained acceptance as 'letting things go', 'being satisfied with constraints' and also 'resign oneself with the idea of having chronic pain'. Interestingly, according to the participants, acceptance or resignation of pain and limitations in daily life can be related to both an increase and a decline in motivation to participate in physical and social activities. For example, some participants accepted the pain and by doing so, they were still motivated to look after the grandchildren or to walk the dog, despite the complaints. In contrast, some other persons with PDN stated that they accepted a restricted life in a wheelchair or even in bed, hereby giving in to the pain, and losing the motivation to be physically or socially active. For those participants, PA caused an increase in pain, which they perceived an as unbearable and uncontrollable pain.

Quote I (male, 51 years, oral medication, married, 7 years of PDN, working in own business, no walking aid): Well, when you make it too easy for people, then they lean backwards and wait until they get help. But that does not help.

Quote II (male, 72 years, insulin treatment, married, 8 years of PDN, retired, no walking aid): The pain remained, but I have become more positive.

Quote III (male, 57 years, oral medication, married, 12 years of PDN, part-time sick leave, wheelchair): I have no more drive. It is not possible to cope with the pain, you cannot control it. The pain rating is so high! I do not even start exercising anymore.

\section{Discussion}

The present study uncovered fears related to diabetes and to pain, and revealed implications that a number of fears and coping strategies of persons with PDN might be 
related. Fears, such as fear of hypoglycaemia, falling, total exhaustion, as well as fear of increased pain, injury, and negative evaluation seem to inhibit physical and social activities. Prior findings confirmed these relationships with regard to fear of hypoglycaemia, which is known as a widespread phenomenon among persons with DMII, and can cause significant negative consequences for diabetes self-management, including avoidance of PA (Green et al., 2000; Wild et al., 2007).

The data from the present study has illustrated possible relationships between fears and avoidance behaviour. Frequently, persons with PDN reported fear of falling as a reason to avoid walking activities, which is in line with earlier research that found changes in walking patterns and a higher risk of falling in persons with PDN (Lalli et al., 2013; van Sloten et al., 2011). Fear of falling could be considered an adaptive mechanism in persons with PDN, as one may also experience sensory loss, resulting in elevated risk for ulcers and gait impairments. Therefore, having no fear at all could result in increased risks of complications such as injuries and ulcerations. Paradoxically, too much fear of falling can lead to dysfunctional and needless restrictions in daily life (Delbaere, Close, Brodaty, Sachdev, \& Lord, 2010), which in turn might lead to less PA and less favourable overall health outcomes. The fear of falling itself has shown to be a risk factor for falls and injury as it may lead to dysfunctional gait adjustments and can lead to avoidance behaviour, activity restriction and subsequent deconditioning (Bruce, Hunter, Peters, Davis, \& Davis, 2015). Interestingly low compared to high levels of fear of falling have shown to be protective for falling, irrespective of the presence of balance impairments (Delbaere et al., 2010). Kelly et al. (2013) discovered that fear of falling was unrelated to the severity of NP. This finding suggests that other reasons than the severity of NP might contribute to a high degree of fear and avoidance behaviour. Studies have shown that exaggerated fear of falling can be treated with a behavioural interventions such as exposure in vivo (Kumar et al., 2016; ScheffersBarnhoorn et al., 2017; Wetherell et al., 2016). In this treatment, the patient will be exposed repeatedly to a situation in which the fear usually occurs. Absence of aversive consequences will lead to extinction of the specific fear (de Jong et al., 2005).

This study revealed statements about helplessness in connection with fears, which corresponds to previous research, demonstrating associations between catastrophic interpretations of pain and avoidance behaviour in persons with other chronic pain syndromes (Vlaeyen \& Linton, 2000). Sullivan et al. (2005) observed that helplessness, a dimension of catastrophizing, was a predictor of pain. Moreover, catastrophic thinking was associated with pain-related disability among persons with NP. A recent study has shown that pain catastrophizing was associated with increased disability and decreased QoL in persons with PDN (Geelen, Kindermans, et al., 2017). Interestingly, pain catastrophizing was associated with the subjective feeling of loss of physical activities due to the pain, while it was not associated with the estimated actual level of activity. Consequently, catastrophic thinking about diabetes and pain-related issues seems to lead to excessive and unnecessary avoidance in persons with PDN.

In this study, the fear of hypoglycaemia was reported as a limiting factor for PA. Williams et al. (2012) described that experiencing even a single hypoglycaemia symptom has a significant impact on a persons' immediate health status with longer-term consequences, e.g. fear of future hypoglycaemia and self-directed behavioural changes 
to manage hypoglycaemia symptoms. In our study, participants explained that they tend to keep their glucose levels somewhat higher in order to prevent an episode of hypoglycaemia. This mechanism of keeping the glucose levels within a 'safety margin' has also been described by Sakane et al. (2015). Di Battista, Hart, Greco, and Gloizer (2009) showed that insulin doses may be inappropriately reduced in anticipation or fear of future hypoglycaemia. This effect is alarming, as maintenance of tight glycaemic control is of great importance in the (self) management of DMII and the prevention of long-term comorbidities associated with DMII (Maser et al., 1989). MartynNemeth et al. (2017) reported significant associations of fear of hypoglycaemia with glycaemic variability, dietary patterns, and PA. Furthermore, fear of hypoglycaemia has been reported to be a major barrier to engage in PA (Brazeau, Rabasa-Lhoret, Strychar, \& Mircescu, 2008), as there may be a perception that certain activities could lead to a higher risk of hypoglycaemia and difficulties managing it (Lascar et al., 2014). Fear of hypoglycaemia itself has shown to be strongly linked to non-diabetes-related anxiety (Anderbro et al., 2015). This is interesting as anxiety symptoms overlap largely with autonomic hypoglycaemia symptoms (sweating, dizziness, palpitations, confusion, being pale, feeling weak, and blurred vision). In this way, hypoglycaemic symptoms could cause an additional trigger for a fear response in people with diabetes (Anderbro et al., 2015), or feelings of fear could be confused with feelings of hypoglycaemia, especially if concomitant anxiety symptoms are already present. Overcoming the fear of hypoglycaemia seems to be of great importance in order to engage in PA, hereby improving glycaemic control and preventing long-term complications.

Acceptance of personal restrictions might be important in coping with PDN. In our study, acceptance seemed to be associated with the acceptance of pain and active coping on the one hand. On the other hand, acceptance indicated an association with restrictions in daily life, fear of more pain and resignation. Current research suggests that acceptance of pain may play an important mediating role in the relationship between chronic pain and functioning, in the manner that acceptance is associated with better outcomes (Akerblom, Perrin, Rivano Fischer, \& McCracken, 2015). As is illustrated in our study, participants may refer to 'acceptance' in two opposite ways, resulting in either an active coping or resignation of the current situation. In the latter interpretation, this so-called acceptance may rather refer to an avoidance coping style. Therefore, it seems to be important to not only address acceptance of pain but also to further elaborate on this topic during consultation.

As confirmed by Ribu and Wahl (2004), persons with PDN were afraid of losing their identity and purpose in life by losing their social roles and responsibilities. Fear of loss of identity arises when the discrepancy between the desired personal situation and the actual situation increases (Kindermans et al., 2011). Van Damme, Crombez, and Eccleston (2008) state that 'task persistence', and 'holding on to unattainable goals', may result in identity confusion in persons with chronic pain syndromes, which confirms statements taken from persons with PDN. However, remaining physically and socially active within personal capabilities was mentioned as a valuable coping strategy in order to retain identity. Therefore, a reappraisal of goals and expectations can be beneficial (Van Damme et al., 2008). Moreover, evidence from Claes, Crombez, and Vlaeyen (2015) illustrated that the pursuit of goals may have an impact on being active despite the pain. 
Consequently, engaging in appropriate activities, setting attainable goals and the determination to achieve personal goals could be beneficial in managing PDN.

Persons with PDN indicated that they experienced no pain when they were cognitively distracted, which is noteworthy, since medicinal treatments for pain reduction are often insufficient and can have side effects (Finnerup et al., 2015; Gilron et al., 2015). Research confirmed that attention to pain can be modulated by performing demanding tasks, and demonstrated that fear of pain can affect this process (Asmundson, Vlaeyen, \& Crombez, 2004). In addition, cognitive distraction has been found to be an important coping strategy in persons with PDN, and further research and clinical application is recommended (Legrain et al., 2009; Valet et al., 2004).

This study provides insightful findings coming from a qualitative research design. As potential limitation it can be mentioned that the sample size was small, although the aims of conducting FGs were to explore cognitions and to generate ideas rather than to establish representativeness. Furthermore, as is the case in qualitative research, analysis showed that saturation was reached, meaning that additional FG would not lead to new information. Finally, it should be noted that this study was performed in a specific population with severe PDN complaints in order to get insights into the full range of physical and psychosocial complaints and underlying processes. This selection could have led to an overrepresentation of fears and beliefs in PDN and may not represent the entire group of persons with PDN. At this point, it is not known whether patients with less severe complaints share the same fears that were identified in the present study.

The novelty of this study is that we have aimed to gain more specific information about the content of various fears that can play a role in restrictions in daily life in persons with PDN. The importance of findings can be considerable, since the participants of the present study were a carefully selected, specific sample of experienced experts with high levels of pain and disability despite medical treatment.

\section{Future studies}

Various non-pharmacological treatment options have been developed that aim to reduce fear and psychological well-being in patients with other chronic pain syndromes (Angst, Brioschi, Main, Lehmann, \& Aeschlimann, 2006; den Hollander et al., 2016; Nijs, Malfliet, Ickmans, Baert, \& Meeus, 2014; Wicksell et al., 2013). Research has shown that multidisciplinary rehabilitation interventions that target factors from the different biopsychosocial domains, administered by healthcare professionals from different backgrounds, are more effective than physical or psychological interventions alone (Kamper et al., 2014).

Numerous studies demonstrate that an effective psychosocial remedy against fears is exposure to the object of the fear. An example of a cognitive behavioural treatment modality is exposure in vivo (EXP), which combines physiotherapy with cognitive behavioural therapy (de Jong et al., 2008; den Hollander et al., 2016; Leeuw et al., 2008; Vlaeyen, Morley, Linton, Boersma, \& de Jong, 2012). EXP specifically targets catastrophic (mis)interpretations of bodily symptoms including pain. These fear-reducing techniques are based on experimental and clinical findings that expectancies about the associations between movements and increased pain can be readjusted and reduced by 
exposing the individual to the feared painful movement (Meulders \& Vlaeyen, 2012; Vlaeyen, de Jong, Leeuw, \& Crombez, 2004; Vlaeyen, Kole-Snijders, Boeren, et al., 1995). EXP treatments have shown to be effective in reducing pain-related fear and the perceived harmfulness of PA in various chronic pain conditions, such as chronic low back pain (de Jong et al., 2005; Leeuw et al., 2008; Vlaeyen, de Jong, Geilen, Heuts, \& van Breukelen, 2002) and chronic regional pain syndrome type I (CRPS-I) (de Jong et al., 2005; den Hollander et al., 2016). Whether EXP is applicable in persons with PDN, is currently being investigated in one of our current ongoing clinical studies. We adopted a single-case experimental design in which persons with PDN receive the EXP treatment by our team that has had additional training regarding the risks and special needs of diabetic persons. For example, blood glucose levels are measured pre- and post-treatment, participants are excluded when having pressure ulcers on their feet and they are screened on wearing adequate (orthopaedic) shoes. Next to the pain related fears, also diabetes (hypoglycaemia) related thoughts and fears are assessed, as we believe that they can be challenged in the same way. As mentioned before, the evaluation of fear of hypoglycaemia is not always irrational and some level of concern can be considered appropriate and adaptive (Anderbro et al., 2015). Anderbro et al. (2015) have suggested that a form of biofeedback training could be helpful in patients with high levels of fear of hypoglycaemia in spite of low levels of hypoglycaemic risk. By addressing thoughts and beliefs about blood glucose levels in relation to the actual measurements of blood glucose levels pre- and post-treatment, diabetic persons will learn to recognise which bodily sensations correspond to the actual blood glucose levels. In a second step, they are encouraged to increase their level of PA and apply their recognition skills in novel situations. This sort of training might be a useful addition to an exposure-based treatment for persons with PDN as explained before. In our opinion, EXP programs in PDN are best carried out by experienced behaviour therapists, in combination with physiotherapist (specialised in DM), and under a physician's supervision.

Next to exposure methods for fear-avoidance related patterns, Acceptance and Commitment Therapy (ACT) (S. C. Hayes, Strosahl, \& Wilson, 2011) might also be a promising avenue to assist adaptive coping with PDN. ACT is a treatment approach, which includes a combination of acceptance and mindfulness methods along with activation and behaviour change methods (McCracken \& Vowles, 2014). ACT is based on the theory that thoughts, beliefs, rules, and instructions, as well as pain or other psychological experiences can narrow the range of an individual's available responses and present obstacles to healthy behaviour and behaviour change (McCracken \& Vowles, 2014). ACT aims to increase psychological flexibility in the context of chronic pain, hereby reducing the influence of personal thoughts, experiences and emotions on daily life functioning. Within this treatment, physical functioning is usually improved according to the principles of graded activity, which is an individualised and submaximal exercise program combined with educational support to enhance selftrust and tolerance to effort (Lindstrom et al., 1992). Multidisciplinary ACT has shown to be effective in reducing the burden of chronic pain in various pain conditions ( $S$. Hayes et al., 2014; Wicksell et al., 2013). ACT is mainly focused on acceptance and dealing with pain and its consequences. However, it does not directly target pain related fears or avoidance behaviours. 


\section{Conclusion}

Based on the data obtained from FG with persons with moderate to severe PDN, diabetes-related fears as well as pain-related fears may have an impact on self-management of persons with PDN. Concepts such as pain catastrophizing, acceptance, goal setting, and cognitive distraction may affect physical activities and social engagements of persons with PDN. The mutual relationship between fears and coping strategies appear to be both functional and dysfunctional.

Based on this study, a few recommendations can be made. For clinical practice, it is recommended to quantify diabetes-related fears as well as pain-related fears, and to take these fears and personal coping strategies into account when treating persons with PDN.

\section{Disclosure statement and funding details}

All procedures performed in this study were in accordance with the Good Clinical Practice guidelines as outlined by the International Conference on Harmonisation and the ethical standards of the institutional and national research committee and with the 1964 Helsinki declaration and its later amendments of comparable ethical standards. Informed consent was obtained from all individual participants included in the study. The authors declare that they have no competing interests.

\section{Acknowledgements}

We thank the editor and reviewers for their valuable contributions to the creation of this manuscript.

\section{Disclosure statement}

No potential conflict of interest was reported by the authors.

\section{Funding}

The present study was funded by the Dutch Diabetes Foundation, grant number 2010.13.1361.

\section{ORCID}

Iris M. Kanera (D) http://orcid.org/0000-0001-6863-2096

Jeanine A. Verbunt (D) http://orcid.org/0000-0002-9060-9455

\section{References}

Aaronson, N. K., Muller, M., Cohen, P. D., Essink-Bot, M. L., Fekkes, M., Sanderman, R., ... Verrips, E. (1998). Translation, validation, and norming of the Dutch language version of the SF-36 Health Survey in community and chronic disease populations. Journal of Clinical Epidemiology, 51(11), 1055-1068.

Abbott, C. A., Malik, R. A., van Ross, E. R., Kulkarni, J., \& Boulton, A. J. (2011). Prevalence and characteristics of painful diabetic neuropathy in a large community-based diabetic population in the U.K. Diabetes Care, 34(10), 2220-2224. doi:10.2337/dc11-1108 
Ahola, A. J., \& Groop, P. H. (2013). Barriers to self-management of diabetes. Diabetics Medicine, 30(4), 413-420. doi:10.1111/dme.12105

Akerblom, S., Perrin, S., Rivano Fischer, M., \& McCracken, L. M. (2015). The mediating role of acceptance in multidisciplinary cognitive-behavioral therapy for chronic pain. Journal of Pain, 16(7), 606-615. doi:10.1016/j.jpain.2015.03.007

Anderbro, T., Gonder-Frederick, L., Bolinder, J., Lins, P. E., Wredling, R., Moberg, E., ... Johansson, U. B. (2015). Fear of hypoglycemia: Relationship to hypoglycemic risk and psychological factors. Acta Diabetologica, 52(3), 581-589. doi:10.1007/s00592-014-0694-8

Angst, F., Brioschi, R., Main, C. J., Lehmann, S., \& Aeschlimann, A. (2006). Interdisciplinary rehabilitation in fibromyalgia and chronic back pain: A prospective outcome study. Journal of Pain, 7(11), 807-815. doi:10.1016/j.jpain.2006.03.009

Asmundson, G. J. G., Vlaeyen, J. W. S., \& Crombez, G. (2004). Understanding and treating fear of pain (1st ed.). New York, NY: Oxford University Press.

Balhara, Y. P., \& Sagar, R. (2011). Correlates of anxiety and depression among patients with type 2 diabetes mellitus. Indian Journal of Endocrinology Metabolism, 15(Suppl.1), S50-S54. doi: 10.4103/2230-8210.83057

Bouhassira, D., Attal, N., Alchaar, H., Boureau, F., Brochet, B., Bruxelle, J., ... Vicaut, E. (2005). Comparison of pain syndromes associated with nervous or somatic lesions and development of a new neuropathic pain diagnostic questionnaire (DN4). Pain, 114(1-2), 29-36. doi:10.1016/ j.pain.2004.12.010

Brazeau, A. S., Rabasa-Lhoret, R., Strychar, I., \& Mircescu, H. (2008). Barriers to physical activity among patients with type 1 diabetes. Diabetes Care, 31(11), 2108-2109. doi:10.2337/dc080720

Brix Finnerup, N., Hein Sindrup, S., \& Staehelin Jensen, T. (2013). Management of painful neuropathies. Handbook of Clinical Neurology, 115, 279-290. doi:10.1016/b978-0-444-52902-2.000175

Brod, M., Tesler, L. E., \& Christensen, T. L. (2009). Qualitative research and content validity: Developing best practices based on science and experience. Quality Life Research, 18(9), 1263-1278. doi:10.1007/s11136-009-9540-9

Bruce, D., Hunter, M., Peters, K., Davis, T., \& Davis, W. (2015). Fear of falling is common in patients with type 2 diabetes and is associated with increased risk of falls. Age Ageing, 44(4), 687-690. doi:10.1093/ageing/afv024

Claes, N., Crombez, G., \& Vlaeyen, J. W. (2015). Pain-avoidance versus reward-seeking: An experimental investigation. Pain, 156(8), 1449-1457. doi:10.1097/j.pain.0000000000000116

Cutcliffe, J. R. (2005). Adapt or adopt: Developing and transgressing the methodological boundaries of grounded theory. Journal of Advanced Nursing, 51(4), 421-428.

de Jong, J. R., Vangronsveld, K., Peters, M. L., Goossens, M. E., Onghena, P., Bulte, I., \& Vlaeyen, J. W. (2008). Reduction of pain-related fear and disability in post-traumatic neck pain: A replicated single-case experimental study of exposure in vivo. Journal of Pain, 9(12), 1123-1134. doi:10.1016/j.jpain.2008.06.015

de Jong, J. R., Vlaeyen, J. W., de Gelder, J. M., \& Patijn, J. (2011). Pain-related fear, perceived harmfulness of activities, and functional limitations in complex regional pain syndrome type $\mathrm{I}$. Journal of Pain, 12(12), 1209-1218. doi:10.1016/j.jpain.2011.06.010

de Jong, J. R., Vlaeyen, J. W., Onghena, P., Cuypers, C., den Hollander, M., \& Ruijgrok, J. (2005). Reduction of pain-related fear in complex regional pain syndrome type I: The application of graded exposure in vivo. Pain, 116(3), 264-275. doi:10.1016/j.pain.2005.04.019

Delbaere, K., Close, J. C. T., Brodaty, H., Sachdev, P., \& Lord, S. R. (2010). Determinants of disparities between perceived and physiological risk of falling among elderly people: Cohort study. $B M J$, 341. doi:10.1136/bmj.c4165

den Hollander, M., Goossens, M., de Jong, J., Ruijgrok, J., Oosterhof, J., Onghena, P., ... Vlaeyen, J. W. (2016). Expose or protect? A randomized controlled trial of exposure in vivo vs pain-contingent treatment as usual in patients with complex regional pain syndrome type 1. Pain. doi: 10.1097/j.pain.0000000000000651 
Dew, K. (2007). A health researcher's guide to qualitative methodologies. Australian New Zealand Journal of Public Health, 31(5), 433-437. doi:10.1111/j.1753-6405.2007.00114.x

Di Battista, A. M., Hart, T. A., Greco, L., \& Gloizer, J. (2009). Type 1 diabetes among adolescents: Reduced diabetes self-care caused by social fear and fear of hypoglycemia. Diabetes Education, 35(3), 465-475. doi:10.1177/0145721709333492

Finnerup, N. B., Attal, N., Haroutounian, S., McNicol, E., Baron, R., Dworkin, R. H., ... Wallace, M. (2015). Pharmacotherapy for neuropathic pain in adults: A systematic review and meta-analysis. Lancet Neurology, 14(2), 162-173. doi:10.1016/s1474-4422(14)70251-0

Geelen, C. C., Brouwer, B. A., Hoeijmakers, J. G., Faber, C. G., Merkies, I. S., \& Verbunt, J. A. (2016). Painful Diabetic Neuropathy Anxiety Rasch-Transformed Questionnaire (PART-Q30((c))). Journal of the Peripheral Nervous System, 21(2), 96-104. doi:10.1111/jns.12162

Geelen, C. C., Kindermans, H. P., van den Bergh, J. P., \& Verbunt, J. A. (2017). Perceived physical activity decline as a mediator in the relationship between pain catastrophizing, disability, and quality of life in patients with painful diabetic neuropathy. Pain Practice, 17(3), 320-328. doi: 10.1111/papr.12449

Geelen, C. C., Smeets, R., Schmitz, S., van den Bergh, J. P., Goossens, M., \& Verbunt, J. A. (2017). Anxiety affects disability and quality of life in patients with painful diabetic neuropathy. European Journal of Pain. doi:10.1002/ejp.1067

Gheldof, E. L., Crombez, G., Van den Bussche, E., Vinck, J., Van Nieuwenhuyse, A., Moens, G., ... Vlaeyen, J. W. (2010). Pain-related fear predicts disability, but not pain severity: A path analytic approach of the fear-avoidance model. European Journal of Pain, 14(8), 870.e871-879. doi:10.1016/j.ejpain.2010.01.003

Gilron, I., Baron, R., \& Jensen, T. (2015). Neuropathic pain: principles of diagnosis and treatment. Mayo Clinic Proceedings, 90(4), 532-545. doi:10.1016/j.mayocp.2015.01.018

Green, L., Feher, M., \& Catalan, J. (2000). Fears and phobias in people with diabetes. Diabetes Metabolism Research and Reviews, 16(4), 287-293.

Hayes, S., Hogan, M., Dowd, H., Doherty, E., O'Higgins, S., Nic Gabhainn, S., ... McGuire, B. E. (2014). Comparing the clinical-effectiveness and cost-effectiveness of an internet-delivered Acceptance and Commitment Therapy (ACT) intervention with a waiting list control among adults with chronic pain: Study protocol for a randomised controlled trial. BMJ Open, 4(7), e005092. doi:10.1136/bmjopen-2014-005092

Hayes, S. C., Strosahl, K. D., \& Wilson, K. G. (2011). Acceptance and commitment therapy: The process and practice of mindful change. New York: Guilford Press.

Heinrich, E., Schaper, N. C., \& de Vries, N. K. (2010). Self-management interventions for type 2 diabetes: A systematic review. European Diabetes Nursing, 7(2), 71-76.

Jain, R., Jain, S., Raison, C. L., \& Maletic, V. (2011). Painful diabetic neuropathy is more than pain alone: Examining the role of anxiety and depression as mediators and complicators. Current Diabetes Reports, 11(4), 275-284. doi:10.1007/s11892-011-0202-2

Jensen, M. P., Karoly, P., \& Braver, S. (1986). The measurement of clinical pain intensity: A comparison of six methods. Pain, 27(1), 117-126.

Kamper, S. J., Apeldoorn, A. T., Chiarotto, A., Smeets, R. J., Ostelo, R. W., Guzman, J., \& van Tulder, M. W. (2014). Multidisciplinary biopsychosocial rehabilitation for chronic low back pain. Cochrane Database System Reviews (9), Cd000963. doi:10.1002/14651858.CD000963.pub3

Kelly, C., Fleischer, A., Yalla, S., Grewal, G. S., Albright, R., Berns, D., ... Najafi, B. (2013). Fear of falling is prevalent in older adults with diabetes mellitus but is unrelated to level of neuropathy. Journal of the American Podiatry Medical Association, 103(6), 480-488.

Kindermans, H. P., Huijnen, I. P., Goossens, M. E., Roelofs, J., Verbunt, J. A., \& Vlaeyen, J. W. (2011). 'Being' in pain: The role of self-discrepancies in the emotional experience and activity patterns of patients with chronic low back pain. Pain, 152(2), 403-409. doi:10.1016/ j.pain.2010.11.009

Kluding, P. M., Pasnoor, M., Singh, R., Jernigan, S., Farmer, K., Rucker, J., ... Wright, D. E. (2012). The effect of exercise on neuropathic symptoms, nerve function, and cutaneous innervation in people with diabetic peripheral neuropathy. Journal of Diabetes and Its Complications, 26(5), 424-429. doi:10.1016/j.jdiacomp.2012.05.007 
Kumar, A., Delbaere, K., Zijlstra, G. A., Carpenter, H., lliffe, S., Masud, T., ... Kendrick, D. (2016). Exercise for reducing fear of falling in older people living in the community: Cochrane systematic review and meta-analysis. Age Ageing, 45(3), 345-352. doi:10.1093/ageing/afw036

Lalli, P., Chan, A., Garven, A., Midha, N., Chan, C., Brady, S., ... Toth, C. (2013). Increased gait variability in diabetes mellitus patients with neuropathic pain. Journal of Diabetes and Its Complications, 27(3), 248-254. doi:10.1016/j.jdiacomp.2012.10.013

Lascar, N., Kennedy, A., Hancock, B., Jenkins, D., Andrews, R. C., Greenfield, S., \& Narendran, P. (2014). Attitudes and barriers to exercise in adults with type 1 diabetes (T1DM) and how best to address them: A qualitative study. PLoS One, 9(9), e108019. doi:10.1371/ journal.pone.0108019

Leeuw, M., Goossens, M. E., van Breukelen, G. J., de Jong, J. R., Heuts, P. H., Smeets, R. J., ... Vlaeyen, J. W. (2008). Exposure in vivo versus operant graded activity in chronic low back pain patients: Results of a randomized controlled trial. Pain, 138(1), 192-207. doi:10.1016/ j.pain.2007.12.009

Legrain, V., Damme, S. V., Eccleston, C., Davis, K. D., Seminowicz, D. A., \& Crombez, G. (2009). A neurocognitive model of attention to pain: Behavioral and neuroimaging evidence. Pain, 144(3), 230-232. doi:10.1016/j.pain.2009.03.020

Lindstrom, I., Ohlund, C., Eek, C., Wallin, L., Peterson, L. E., \& Nachemson, A. (1992). Mobility, strength, and fitness after a graded activity program for patients with subacute low back pain. A randomized prospective clinical study with a behavioral therapy approach. Spine (Phila Pa 1976), 17(6), 641-652.

Martyn-Nemeth, P., Quinn, L., Penckofer, S., Park, C., Hofer, V., \& Burke, L. (2017). Fear of hypoglycemia: Influence on glycemic variability and self-management behavior in young adults with type 1 diabetes. Journal of Diabetes and Its Complications, 31(4), 735-741. doi:10.1016/ j.jdiacomp.2016.12.015

Maser, R. E., Steenkiste, A. R., Dorman, J. S., Nielsen, V. K., Bass, E. B., Manjoo, Q., ... et al. (1989). Epidemiological correlates of diabetic neuropathy. Report from Pittsburgh Epidemiology of Diabetes Complications Study. Diabetes, 38(11), 1456-1461.

McCoy, R. G., Van Houten, H. K., Ziegenfuss, J. Y., Shah, N. D., Wermers, R. A., \& Smith, S. A. (2013). Self-report of hypoglycemia and health-related quality of life in patients with type 1 and type 2 diabetes. Endocrine Practice, 19(5), 792-799. doi:10.4158/ep12382.or

McCracken, L. M., \& Vowles, K. E. (2014). Acceptance and commitment therapy and mindfulness for chronic pain: Model, process, and progress. American Psychologist, 69(2), 178-187. doi: 10.1037/a0035623

Meijer, J. W., Smit, A. J., Sonderen, E. V., Groothoff, J. W., Eisma, W. H., \& Links, T. P. (2002). Symptom scoring systems to diagnose distal polyneuropathy in diabetes: The Diabetic Neuropathy Symptom score. Diabetic Medicine, 19(11), 962-965.

Meulders, A., \& Vlaeyen, J. W. (2012). Reduction of fear of movement-related pain and painrelated anxiety: An associative learning approach using a voluntary movement paradigm. Pain, 153(7), 1504-1513.

Morgan, D. L., \& Krueger, R. A. (1998). Analyzing and reporting focus group results (Vol.6). Thousand Oaks, CA: Sage.

Morrato, E. H., Hill, J. O., Wyatt, H. R., Ghushchyan, V., \& Sullivan, P. W. (2007). Physical activity in U.S. adults with diabetes and at risk for developing diabetes, 2003. Diabetes Care, 30(2), 203-209. doi:10.2337/dc06-1128

Mortelmans, M. (2011). Kwalitatieve Analyse met NVivo. Leuven: Acco Uitgeverij.

Nam, S., Tin, D., Bain, L., Thorne, J. C., \& Ginsburg, L. (2014). Clinical utility of the Hospital Anxiety and Depression Scale (HADS) for an Outpatient Fibromyalgia Education Program. Clinical Rheumatology, 33(5), 685-692. doi:10.1007/s10067-013-2377-1

Nijs, J., Malfliet, A., Ickmans, K., Baert, I., \& Meeus, M. (2014). Treatment of central sensitization in patients with 'unexplained' chronic pain: An update. Expert Opinion on Pharmacotherapy, 15(12), 1671-1683. doi:10.1517/14656566.2014.925446

NVivo qualitative data analysis software version 8. (2008). Melbourne, Australia: QSR International Pty Ltd. 
Petrak, F. (2007). Diabetes und Angst-Haben Patienten mit Diabetes zu viel oder zu wenig Angst? Diabetes aktuell, 5(06), 255-259.

Ribu, L., \& Wahl, A. (2004). Living with diabetic foot ulcers: A life of fear, restrictions, and pain. Ostomy Wound Management, 50(2), 57-67.

Roelofs, J., Goubert, L., Peters, M. L., Vlaeyen, J. W., \& Crombez, G. (2004). The Tampa Scale for Kinesiophobia: Further examination of psychometric properties in patients with chronic low back pain and fibromyalgia. European Journal of Pain, 8(5), 495-502.

Sadosky, A., Schaefer, C., Mann, R., Bergstrom, F., Baik, R., Parsons, B., ... Tuchman, M. (2013). Burden of illness associated with painful diabetic peripheral neuropathy among adults seeking treatment in the US: Results from a retrospective chart review and cross-sectional survey. Diabetes Metabolic Syndrome and Obesity, 6, 79-92. doi:10.2147/dmso.s37415

Sakane, N., Kotani, K., Tsuzaki, K., Nishi, M., Takahashi, K., Murata, T., ... Yamamoto, T. (2015). Fear of hypoglycemia and its determinants in insulin-treated patients with type 2 diabetes mellitus. Journal of Diabetes Investigation, 6(5), 567-570. doi:10.1111/jdi.12340

Scheffers-Barnhoorn, M. N., van Haastregt, J. C., Schols, J. M., Kempen, G. I., van Balen, R., Visschedijk, J. H., ... van Eijk, M. (2017). A multi-component cognitive behavioural intervention for the treatment of fear of falling after hip fracture (FIT-HIP): Protocol of a randomised controlled trial. BMC Geriatrics, 17(1), 71. doi:10.1186/s12877-017-0465-9

Smith, J. A. (2015). Qualitative psychology: A practical guide to research methods. London, UK: Sage.

Soer, R., Koke, A. J., Vroomen, P. C., Stegeman, P., Smeets, R. J., Coppes, M. H., \& Reneman, M. F. (2013). Extensive validation of the pain disability index in 3 groups of patients with musculoskeletal pain. Spine (Phila Pa 1976), 38(9), E562-568. doi:10.1097/BRS.0b013e31828af21f

Spallone, V., Morganti, R., D'Amato, C., Greco, C., Cacciotti, L., \& Marfia, G. A. (2012). Validation of DN4 as a screening tool for neuropathic pain in painful diabetic polyneuropathy. Diabetic Medicine, 29(5), 578-585. doi:10.1111/j.1464-5491.2011.03500.x

Sullivan, M. J. R., Bishop, S. R., \& Pivik, J. (1995). The pain catastrophizing scale: Development and validation. Psychological Assessment, 7(4), 524.

Sullivan, M. J, Lynch, , M. E., \& Clark, A. J. (2005). Dimensions of catastrophic thinking associated with pain experience and disability in patients with neuropathic pain conditions. Pain, 113(3), 310-315.

Swinkels-Meewisse, E. J., Swinkels, R. A., Verbeek, A. L., Vlaeyen, J. W., \& Oostendorp, R. A. (2003). Psychometric properties of the Tampa Scale for kinesiophobia and the fear-avoidance beliefs questionnaire in acute low back pain. Manual Therapy, 8(1), 29-36.

Tait, R. C., Chibnall, J. T., \& Krause, S. (1990). The Pain Disability Index: Psychometric properties. Pain, 40(2), 171-182.

Tong, A., Sainsbury, P., \& Craig, J. (2007). Consolidated criteria for reporting qualitative research (COREQ): A 32-item checklist for interviews and focus groups. International Journal of Quality in Health Care, 19(6), 349-357. doi:10.1093/intqhc/mzm042

Valet, M., Sprenger, T., Boecker, H., Willoch, F., Rummeny, E., Conrad, B., ... Tolle, T. R. (2004). Distraction modulates connectivity of the cingulo-frontal cortex and the midbrain during pain - an fMRI analysis. Pain, 109(3), 399-408. doi:10.1016/j.pain.2004.02.033

Van Acker, K., Bouhassira, D., De Bacquer, D., Weiss, S., Matthys, K., Raemen, H., ... Colin, I. M. (2009). Prevalence and impact on quality of life of peripheral neuropathy with or without neuropathic pain in type 1 and type 2 diabetic patients attending hospital outpatients clinics. Diabetes Metabolism, 35(3), 206-213. doi:10.1016/j.diabet.2008.11.004

Van Damme, S., Crombez, G., Bijttebier, P., Goubert, L., \& Van Houdenhove, B. (2002). A confirmatory factor analysis of the Pain Catastrophizing Scale: Invariant factor structure across clinical and non-clinical populations. Pain, 96(3), 319-324.

Van Damme, S., Crombez, G., \& Eccleston, C. (2008). Coping with pain: A motivational perspective. Pain, 139(1), 1-4. doi:10.1016/j.pain.2008.07.022

van Seventer, R., Vos, C., Giezeman, M., Meerding, W. J., Arnould, B., Regnault, A., ... Huygen, F. (2013). Validation of the Dutch version of the DN4 diagnostic questionnaire for neuropathic pain. Pain Practice, 13(5), 390-398. doi:10.1111/papr.12006 
van Sloten, T. T., Savelberg, H. H., Duimel-Peeters, I. G., Meijer, K., Henry, R. M., Stehouwer, C. D., \& Schaper, N. C. (2011). Peripheral neuropathy, decreased muscle strength and obesity are strongly associated with walking in persons with type 2 diabetes without manifest mobility limitations. Diabetes Research and Clinical Practice, 91(1), 32-39.

Vlaeyen, J., \& Linton, S. J. (2000). Fear-avoidance and its consequences in chronic musculoskeletal pain: A state of the art. Pain, 85(3), 317-332.

Vlaeyen, J., Morley, S., Linton, S. J., Boersma, K., \& de Jong, J. (2012). Pain-related fear: Exposure based treatment for chronic pain. Seattle (WA): IASP Press.

Vlaeyen, J. W., de Jong, J., Geilen, M., Heuts, P. H., \& van Breukelen, G. (2002). The treatment of fear of movement/(re)injury in chronic low back pain: further evidence on the effectiveness of exposure in vivo. Clinical Journal of Pain, 18(4), 251-261.

Vlaeyen, J. W., de Jong, J., Leeuw, M., \& Crombez, G. (2004). Fear reduction in chronic pain: Graded exposure in vivo with behavioral experiments. In Understanding and treating fear of pain (pp. 313-343). New York: Oxford University Press.

Vlaeyen, J. W., Kole-Snijders, A. M., Boeren, R. G., \& van Eek, H. (1995). Fear of movement/(re)injury in chronic low back pain and its relation to behavioral performance. Pain, 62(3), 363-372.

Vlaeyen, J. W., Kole-Snijders, A. M., Rotteveel, A. M., Ruesink, R., \& Heuts, P. H. (1995). The role of fear of movement/(re)injury in pain disability. Journal of Occupational Rehabilitation, 5(4), 235-252. doi:10.1007/bf02109988

Ware, J. E., Jr., \& Sherbourne, C. D. (1992). The MOS 36-item short-form health survey (SF-36). I. Conceptual framework and item selection. Medical Care, 30(6), 473-483.

Ware, J. E., Kosinski, M., Dewey, J. E., \& Gandek, B. (2000). SF-36 health survey: Manual and interpretation guide. Lincoln, Rl: Quality Metric Inc.

Wetherell, J. L., Johnson, K., Chang, D., Ward, S. R., Bower, E. S., Merz, C., \& Petkus, A. J. (2016). Activity, balance, learning, and exposure (ABLE): A new intervention for fear of falling. International Journal of Geriatric Psychiatry, 31(7), 791-798. doi:10.1002/gps.4393

Wicksell, R. K., Kemani, M., Jensen, K., Kosek, E., Kadetoff, D., Sorjonen, K., ... Olsson, G. L. (2013). Acceptance and commitment therapy for fibromyalgia: A randomized controlled trial. European Journal of Pain, 17(4), 599-611. doi:10.1002/j.1532-2149.2012.00224.x

Wild, D., von Maltzahn, R., Brohan, E., Christensen, T., Clauson, P., \& Gonder-Frederick, L. (2007). A critical review of the literature on fear of hypoglycemia in diabetes: Implications for diabetes management and patient education. Patient Education and Counselling, 68(1), 10-15. doi:10.1016/j.pec.2007.05.003

Williams, S. A., Shi, L., Brenneman, S. K., Johnson, J. C., Wegner, J. C., \& Fonseca, V. (2012). The burden of hypoglycemia on healthcare utilization, costs, and quality of life among type 2 diabetes mellitus patients. Journal of Diabetes and Its Complications, 26(5), 399-406. doi:10.1016/ j.jdiacomp.2012.05.002

Wittink, H., Turk, D. C., Carr, D. B., Sukiennik, A., \& Rogers, W. (2004). Comparison of the redundancy, reliability, and responsiveness to change among SF-36, Oswestry Disability Index, and Multidimensional Pain Inventory. Clinical Journal of Pain, 20(3), 133-142.

Zelman, D. C., Dukes, E., Brandenburg, N., Bostrom, A., \& Gore, M. (2005). Identification of cutpoints for mild, moderate and severe pain due to diabetic peripheral neuropathy. Pain, 115(1-2), 29-36. doi:10.1016/j.pain.2005.01.028

Zelman, D. C., Gore, M., Dukes, E., Tai, K. S., \& Brandenburg, N. (2005). Validation of a modified version of the brief pain inventory for painful diabetic peripheral neuropathy. Journal of Pain and Symptom Management, 29(4), 401-410. doi:10.1016/j.jpainsymman.2004.06.018

Zigmond, A. S., \& Snaith, R. P. (1983). The hospital anxiety and depression scale. Acta Psychiatrica Scandinavica, 67(6), 361-370. 